\title{
FENOLOGIA E PRODUTIVIDADE DO INGÁ-CIPÓ (Inga edulis) NA AMAZÔNIA CENTRAL
}

\author{
Martha de Aguiar FALCÃO', Charles R. CLEMENT ${ }^{2}$
}

Resumo - O ingá-cipó (Inga edulis Martius) é uma leguminosa arbórea da sub-familia Mimosoideae, nativa da América Tropical, e amplamente cultivada pela população local por fornecer fruto comestivel, madeira boa para lenha, como árvore de sombra, e mais recentemente como componente agroflorestal. $\mathrm{O}$ estudo da fenologia do ingá-cipó ajudará a planejar a comercialização dos frutos e o manejo dos plantios. Observou-se quatro períodos de floração durante o ano, com picos em março, maio, agosto/setembro, outubro/janeiro; algumas árvores apresentaram cinco florações. Os picos de frutificação ocorreram $\mathrm{em}$ abril, junho, setembro/ outubro, novembro/fevereiro. Os ingá-cipós de 3-4 anos produziram de 20.000 a 100.000 flores (média de 50.000) e 200 a 800 frutos (média de 500). O vingamento dos frutos variou de 0,4 a $1,8 \%$, com uma média geral de $1,1 \%$. O peso dos frutos variou de 250 a $600 \mathrm{~g}$ (média de $470 \mathrm{~g}$ ), contendo $22 \pm 4 \%$ de polpa comestivel. A produção anual de frutos por árvore variou de $300 \mathrm{a}$ $1.700 \mathrm{~kg}$ (média de $960 \mathrm{~kg}$ ).

Palavras-chave: floração, frutificação, mudança foliar, vingamento, produção de frutos

\section{Phenology and Productivity of Ingá (Inga edulis) in Central Amazonia}

\begin{abstract}
The inga (Inga edulis Martius) is a tree legume in the sub-family Mimosoideae, native to Tropical America, and widely used by the population for its fruits, wood, shade, and, more recently, as an agroforestry component. The study of ingá's phenology may help to plan fruit commercialization and plantation management. Four flowering periods were observed during the year, with flowering peaks in March, May, August/September, October/Dezember, with some trees presenting five flowering peaks, followed by fruiting periods in April, June, September/October, and November/January. Three to four year old ingá trees produce from 20,000 to 100,000 flowers (mean of 50,000) and 200 to 800 fruits (mean of 500). Fruit set varied from 0.4 to $1.8 \%$, with a mean of $1.1 \%$. Fruit weight varied from 250 to $600 \mathrm{~g}$ (mean $470 \mathrm{~g}$ ), with only $22 \pm 4 \%$ edible pulp. Annual fruit yield per tree varied from 300 to $1,700 \mathrm{~kg}$ (mean of $960 \mathrm{~kg}$ ).
\end{abstract}

Key-words: flowering, fruiting, leaf change, fruit set, yield

\section{INTRODUÇÃO}

O ingá-cipó (Inga edulis Martius) é uma leguminosa arbórea da sub-familia Mimosoideae, nativo da América Tropical, e amplamente cultivada pela população local por seu fruto comestivel, que possui sarcotesta comestivel, dá boa lenha e produz sombra (Patiño, 1963; Prance \& Silva, 1975), e mais recentemente vem sendo usado como componente agroflorestal (Salazar et al., 1993). Possivelmente os Ameríndios na Amazônia ocidental o domesticaram (Ducke, 1946; Clement, 1989), pois os frutos nesta região são muito maiores que a média advindos de outros locais. Amplamente distribuida e cultivada na Amazônia e na América Central, a espécie possui muitos nomes vulgares, mostrando a sua importância para a

'Bolsista do PCI do Instituto Nacional de Pesquisas da Amazônia, modalidade DTI. Av. Col.

Teixeira, 386, Cond. Rio Tupana, B1 A, Apto. 602 - Nova Esperança, 69030-456 Manaus, AM, Brasil

${ }^{2}$ Instituto Nacional de Pesquisas da Amazônia, Cx. Postal 478, 69011-970 Manaus, AM, Brasil 
população interiorana: ingá, ingácipó, ingá-de-metro, ingá-doce, ingáde-macaco, ingá-macarrão, rabo-demico (Brasil); guamo, guama (Colombia, Venezuela, Costa Rica); pacae soga, pacae silvestre (Peru) (Prance \& Silva, 1975; Pennington, 1997).

$\mathrm{O}$ ingá-cipó é de porte médio a alto, de crescimento rápido, chegando a $15-20 \mathrm{~m}$ de altura em locais abertos e até $40 \mathrm{~m}$ na floresta. Aos três anos, em locais abertos, inicia a floração e a frutificação. As inflorescências são axilares, algumas vezes terminais, agrupadas, apresentando de 4 a 5 espigas nas axilas das folhas. As flores são brancas, atraentes e perfumadas. $\mathrm{O}$ fruto é uma vagem comprida, de tamanho variável, indeiscente, verde, cilíndrica, espessa, multissucada longitudinalmente, podendo atingir $2 \mathrm{~m}$ de comprimento. As sementes são negras, em número variável por fruto, revestidas por uma sarcotesta branca, flocosa, suculenta, adocicada e comestivel. A germinação é precoce, ocorrendo ás vezes dentro do fruto (Prance \& Silva, 1975; Villachica, 1996; Pennington, 1997).

$\mathrm{O}$ ingá-cipó é apreciado pela população da Amazônia principalmente por seus frutos comestiveis, muito procurados pelas crianças. Os frutos são disponiveis nos mercados locais frequentemente ao longo do ano (Cavalcante, 1991), sugerindo diversos picos de produção, embora este fato não tenha sido ainda relatado na literatura. A espécie está sendo muito usada em sistemas agroflorestais (Salazar et al., 1993) para sombrear cultivos econômicos, como café, cacau, cupuaçu e outros, e a biomassa pode ser aproveitada como forragem e como adubo verde. A floração do ingá-cipó atrai as abelhas melíferas, aumentando em muito a produção das colméias (Fonseca, 1954). Sua madeira branca é empregada em carpintaria leve e na fabricação de caixas; sua lenha queima quente e dá excelente carvão (Corrêa, 1926). Da polpa do fruto prepara-se um xarope usado na medicina caseira contra bronquites e a decocção da casca é empregada na cura de feridas e diarréias (Prance \& Silva, 1975). A casca é rica em tanino e serve para curtume (Prance \& Silva, 1975).

Por ser uma fruteira com potencial agroflorestal, o estudo da fenologia do ingá-cipó ajudará a planejar a comercialização dos frutos e o manejo dos plantios. O objetivo deste trabalho foi estudar a fenologia e a produtividade dos frutos do ingá cipó na Amazônia central, bem como identificar alguns dos insetos visitantes, para subsidiar estudos sobre a sua biologia reprodutiva.

\section{MATERIAL E MÉTODOS}

As observações fenológicas do ingá-cipó foram realizadas durante 18 meses em dez árvores com três a quatro anos de idade, selecionadas ao acaso, num plantio heterogêneo na Fazenda NAF6, no km 14 da BR-174, municipio de Manaus, Amazonas, Brasil. Como a maioria dos ingá cipós da Amazônia, as árvores foram propagadas por sementes de frutos obtidos no local.

Ribeiro (1976) definiu o clima 
de Manaus como "Afi" no esquema de Köppen, embora Ribeiro \& Adis (1984) explicaram que existe variação na precipitação que cai em uma área determinada dentro da região. Os dados climáticos (Fig. 1.A) foram obtidos na Estação Metereológica da Reserva Florestal Adolfo Ducke, do Instituto Nacional de Pesquisas da Amazônia, a 30 km da Fazenda NAF6, $\mathrm{e}$, portanto, podem não ser exatamente iguais aos da área experimental. Ranzani (1980) classificou um solo similar ao da área experimental como um latossolo amarelo, de textura média, e, por analogia, acredita-se que esta classificação e descrição possa ser usada neste caso.

As observações fenológicas foram iniciadas na primeira semana de março de 1977 e continuadas até a última semana de agosto de 1978, com a metodologia usada nos trabalhos anteriores (Falcão, 1983). Em resumo, a floração, frutificação e mudança foliar foram observadas semanalmente, usando-se os seguintes códigos para aproximar as fenofases: 1 - inicio da floração, 2 - plena floração, 3 - fim da floração, 4 - frutos imaturos, 5 - frutos maduros, 6 - folhas novas, 7 - folhas caídas. Na época do pico da segunda floração de 1977, ocorrida no mes de maio, foram contados os botões florais e flores em três galhos/planta, escolhidas ao acaso, e o número total extrapolado para a árvore inteira com base no número total de galhos. Durante a segunda safra de 1977 , ocorrida no mês de junho, uma amostra de 25 frutos maduros de cada árvore foi pesada, separando-se em seguida a casca, sementes e polpa que também foram pesadas separadamente. Os insetos visitantes foram capturados durante a primeira floração de 1978, ocorrida no mês de março, fixados e montados para identificação pelos Drs. Norman Penny, na época pertencente ao Depto. de Entomologia do INPA, João Camargo, da Faculdade de Medicina de Ribeirão Preto, e Jesus S. Moura, da Universidade Federal da Bahia.

\section{RESULTADOS E DISCUSSÃO}

No inicio das observações fenológicas, as plantas estavam com 3-4 anos no campo, apresentando altura aproximada de 4-5 $\mathrm{m}$ e diâmetro da copa de 3-4 m. Estavam em pleno crescimento e não apresentavam problemas fitossanitários. A seguir, apresenta-se o comportamento fenológico do ingá-cipó.

\section{Floração}

$\mathrm{Na}$ maioria das árvores, observou-se quatro períodos de floração durante o ano (Fig. 1.B), com picos de floração em março, maio, agosto/setembro, outubro/janeiro. Algumas árvores apresentaram cinco periodos de floração, com o quinto pico ocorrendo no final do ano. Observou-se moderada variação entre as plantas nas florações que ocorreram na época chuvosa (março e maio), e variação bem maior nas florações que ocorreram na época seca e inicio da época chuvosa. A última floração do ano foi especialmente variável por ter apresentado um pico adicional de floração em algumas plantas. O araçá- 


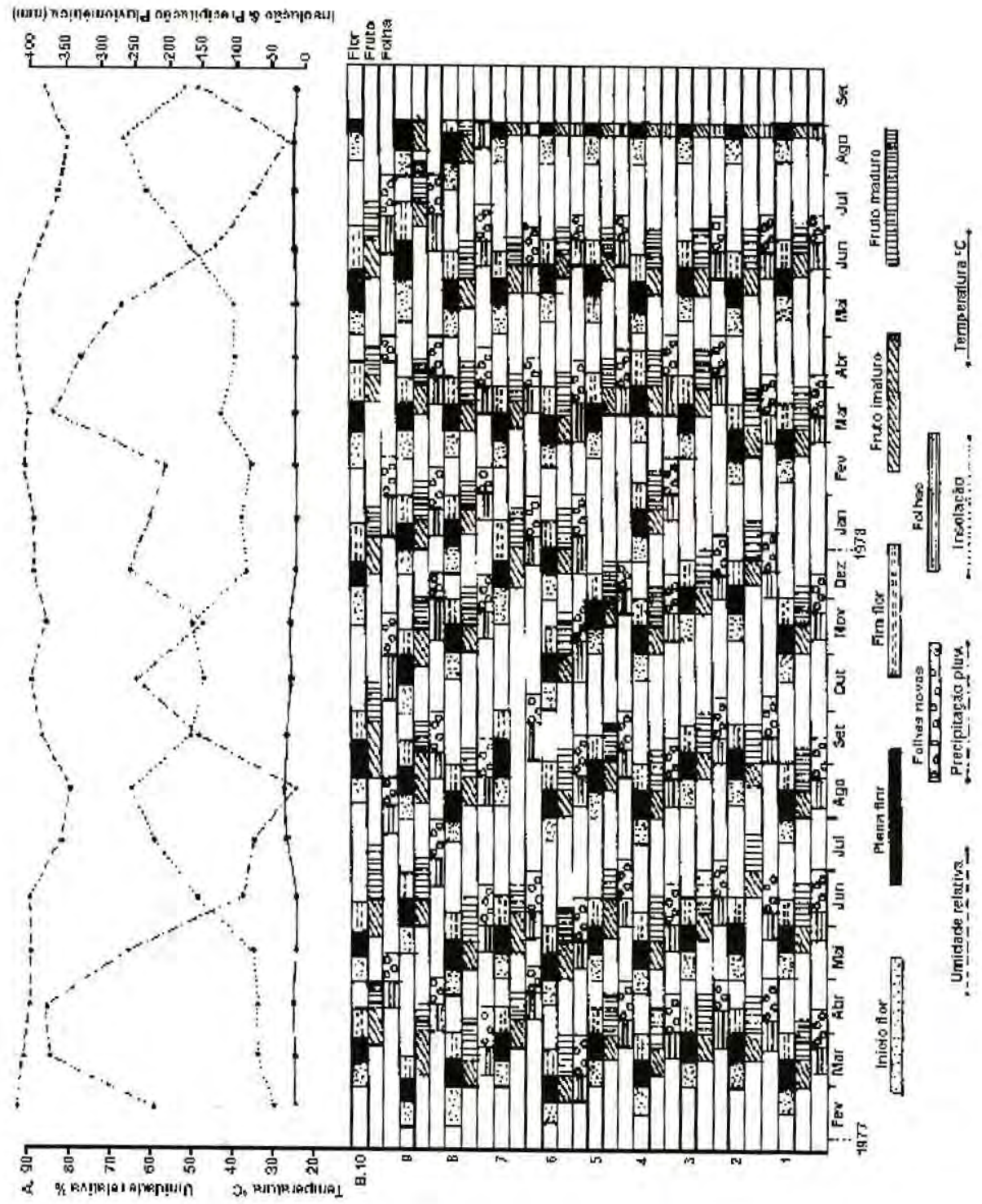

Figura 1.A. Dados climáticos da Estação Metereológica da Reserva Florestal Adolfo Ducke a $30 \mathrm{~km}$ do local das observaçôes fenológicas. B. Fenofases de dez árvores cultivadas de ingá cipó (Inga edulis) entre fevereiro de 1977 e agosto de 1978 em Manaus, AM. 
boi (Eugenia stipitata McVaugh; Falcão et al., 1988) e o abiu (Pouteria caimito Radlk; Falcão \& Clement, 1999) têm comportamento similar, desenvolvendo ciclos de florações sucessivas durante o ano, enquanto a grande maioria das fruteiras amazônicas estudadas até hoje apresenta uma só floração anual (Falcão, 1983; 1993).

As flores se abrem gradativamente na madrugada e a sua duração é de apenas um dia. No dia seguinte, elas murcham e caem, ou secam e ficam presas na base da inflorescência, se não forem polinizadas.

\section{Frutificação}

O ingá-cipó apresentou picos de produção em abril, junho, setembro/ outubro e novembro/fevereiro (Figura 1.B), com os frutos amadurecendo 46 semanas após a floração. Devido à variação entre as plantas, formam-se frutos durante 8 ou 9 meses no ano, conforme comentado por Prance \& Silva (1975) e Cavalcante (1991).

\section{Mudança Foliar}

A queda parcial das folhas ocorreu durante a frutificação e as folhas novas surgiram no início da floração (Fig. 1.B), como na maioria das espécies estudadas por Falcão (1983; 1993). Em muitas espécies a queda ocorre neste periodo, porque as folhas exportam a maioria de seus fotoassimilados para os frutos em crescimento, bem como uma parte de suas reservas nutricionais, para em seguida entrarem em senescência e cairem (Falcão, 1993).

\section{Vingamento}

Os ingás-cipó de 3-4 anos produziram entre 20.000 a 100.000 flores (com média de 50.000) e 200 a 800 frutos (com média de 500) (Tab. 1). O vingamento variou de 0,4 a $1,8 \%$, com média geral de $1,1 \%$. Estas percentagens de vingamento são similares às observadas no cupuaçu $(0,55 \%)$ (Theobroma grandiflorum Schum.; Falcão \& Lleras, 1983) e no abiu (média de 3\%, variação de 2 a $4 \%$ no melhor ano; Falcão \& Clement, 1999).

\section{Produtividade}

Os frutos variaram de tamanho e peso, dentro e entre as plantas (Tab. 2). $\mathrm{O}$ peso dos frutos variou de 250 a 600 $\mathrm{g}$ (com média de $470 \mathrm{~g}$ ), chegando a mais de $1 \mathrm{~m}$ de comprimento. Pennington (1997) relatou que existem frutos na Amazônia peruana com até $2 \mathrm{~m}$ de comprimento. A maior parte do peso dos frutos foi de casca (média de $53 \%$ ) e sementes (média de $24 \%$ ), com apenas $22 \pm 4 \%$ de polpa. A produção anual de frutos por árvore variou de 300 a $1.700 \mathrm{~kg}$ (média de 960 $\mathrm{kg}$ ), assumindo-se quatro ciclos de frutificação de igual intensidade. Esta produção é muito superior aos $45 \mathrm{~kg}$ relatados por Villachica (1996), embora não tenha ficado claro se ele se referia a apenas uma safra ou um ano.

\section{Insetos visitantes}

As flores foram visitadas por abelhas, vespas, formigas, borboletas (Tab. 3), beija-flores e mariposas (não identificadas). As abelhas foram 
Tabela 1. Estimativos dos números de flores e frutos, e porcentagens de vingamento de frutos em ingá cipó (Inga edulis) com 3 a 4 anos de idade na safra de maio/junho de 1977 em Manaus, AM.

\begin{tabular}{cccc}
\hline Árvore & Número Flores & Número Frutos & Vingamento (\%) \\
\hline 1 & 52.348 & 205 & 0,39 \\
2 & 28.110 & 260 & 0,92 \\
3 & 36.189 & 649 & 1,79 \\
4 & 69.935 & 675 & 0,97 \\
5 & 42.880 & 680 & 1,59 \\
6 & 100.118 & 840 & 0,84 \\
7 & 75.628 & 790 & 1,04 \\
8 & 20.304 & 330 & 1,63 \\
9 & 41.500 & 420 & 1,01 \\
10 & 35.253 & 390 & 1,11 \\
Média & $50.227 \pm 23.374$ & $524 \pm 217$ & $1,13 \pm 0,40$ \\
\hline
\end{tabular}

Tabela 2. Peso médio ( \pm desvio padrão) dos frutos de ingá cipó (Inga edulis) e de seus componentes, e estimativas de produção de frutos (assumindo 4 frutificações iguais) dentre e entre árvores em Manaus, AM, em junho de 1977.

\begin{tabular}{ccccccc}
\hline & Fruto & Casca & Semente & Polpa & $\begin{array}{c}\text { Polpa } \\
\text { Árv. }\end{array}$ & \multicolumn{3}{c}{$(\mathrm{g})$} & $\begin{array}{c}\text { Produção } \\
\text { (kg/árv.) }\end{array}$ \\
\cline { 2 - 4 } 1 & $388 \pm 110$ & $210 \pm 71$ & $90 \pm 30$ & $88 \pm 44$ & 22,7 & 318 \\
2 & $619 \pm 143$ & $293 \pm 74$ & $153 \pm 33$ & $173 \pm 66$ & 27,9 & 644 \\
3 & $287 \pm 69$ & $167 \pm 52$ & $55 \pm 11$ & $65 \pm 17$ & 22,6 & 745 \\
4 & $258 \pm 53$ & $167 \pm 50$ & $46 \pm 8$ & $45 \pm 14$ & 17,4 & 697 \\
5 & $544 \pm 154$ & $258 \pm 72$ & $132 \pm 52$ & $155 \pm 50$ & 28,5 & 1480 \\
6 & $506 \pm 127$ & $277 \pm 85$ & $143 \pm 36$ & $86 \pm 32$ & 17,0 & 1700 \\
7 & $549 \pm 82$ & $311 \pm 44$ & $128 \pm 29$ & $111 \pm 40$ & 20,2 & 1735 \\
8 & $584 \pm 87$ & $313 \pm 54$ & $122 \pm 24$ & $149 \pm 31$ & 25,5 & 771 \\
9 & $576 \pm 118$ & $320 \pm 76$ & $147 \pm 36$ & $110 \pm 24$ & 19,1 & 968 \\
10 & $395 \pm 81$ & $209 \pm 48$ & $101 \pm 23$ & $86 \pm 20$ & 21,8 & 616 \\
Média & $471 \pm 123$ & $252 \pm 57$ & $112 \pm 36$ & $107 \pm 39$ & $22,3 \pm 3,8$ & $967 \pm 469$ \\
\hline
\end{tabular}


Tabela 3. Insetos visitantes das flores de ingá cipó (Inga edulis) coletados em 10 árvores cultivadas em Manaus, AM, em 1978.

\begin{tabular}{ll}
\hline Ordem: Familia & Espécies \\
\hline Hymenoptera: Apidae (Abelhas) & Brachygastra sp. \\
& Melipona sp. \\
& Oxytrigona obscura \\
& Partamona pseudomusarcim \\
& Tetragona (Pfilotrigona) lurida \\
Hymenoptera: Formicidae (Formigas) & Camponotus sp. \\
Lepidoptera: Heliconiidae (Borboletas) & Heliconius numata \\
\hline
\end{tabular}

especialmente abundantes, com um grupo de espécies visitando ao amanhecer e outro grupo no horário de 9:00/10:00 até 12:00, sugerindo que a maioria da polinização ocorre pela manhã, embora não tenha ficado claro qual o grupo de abelhas mais eficientes. Nenhum dos insetos visitantes pareceu ser uma praga importante. A visita dos beija-flores também se deu pela manhã.

\section{CONCLUSÕES}

$\mathrm{O}$ ingá-cipó apresentou quatro florações durante o ano na Amazônia central, embora algumas plantas possam florecer cinco vezes. Isto faz com que o ingá-cipó também apresente quatro frutificações por ano, com alguns frutos disponiveis no mercado durante pelo menos 8 a 9 meses. A produtividade anual de frutos de ingá-cipó é muito variável (300 a $1.700 \mathrm{~kg}$ ).

\section{AGRADECIMENTOS}

Agradecemos à $\mathrm{Dr}^{\mathrm{a}}$ Marlene Freitas da Silva e ao M.Sc. Luis Augusto Gomes de Souza pela leitura critica do manuscrito e as sugestões oferecidas, e aos referees e editor assistente da Acta Amazonica para suas sugestões para melhorar a qualidade da apresentação.

\section{Bibliografia Citada}

Cavalcante, P.B. 1991. Frutas comestiveis da Amazônia, 5a ed. Belém, Museu Paraense Emílio Goeldi. 279 p.

Clement, C.R. 1989. A center of crop genetic diversity in western Amazonia. BioScience, 39(9):624-631.

Corrêa, M.P. 1926. Dicionário das plantas úteis do Brasil e das exóticas cultivadas (6 volumes). Rio de Janeiro, Serviço de Informação Agrícola.

Ducke, A. 1946. Plantas de cultura préColombiana na Amazônia brasileira. Boletim Técnico do Instituto Agronômico do Norte, 8:1-24. 
Falcão, M.A. (ed.) 1979. Aspectos fenológicos, ecológicos e de produtividade de algumas fruteiras cultivadas na Amazônia. Vol. 1. Manaus, Amazonas, Editora Umberto Calderaro e SUFRAMA. 201 p.

Falcão, M.A. (ed.) 1993. Aspectos fenológicos, ecológicos, e de produtividade de algumas fruteiras cultivadas na Amazônia. Vol. II. Manaus, Amazonas, Fundação Universidade do Amazonas, 97 p.

Falcão, M.A.; Chávez F., W.B.; Ferreira, S.A.N.; Barros, M.J.B.; Brito, J.M.C.; Santos, T.C.T. 1988. Aspectos fenológicos e ecológicos do araçá-boi (Eugenia stipitata McVaugh) na Amazônia Central. 1. Plantas juvenis. Acta Amazonica, 18(34):27-38.

Falcão, M.A.; Clement, C.R. 1999. Fenologia e produtividade do abiu (Pouteria caimito) na Amazônia Central. Acta Amazonica, 29(1):3-12.

Falcão, M.A.; Lleras, E. 1983. Aspectos fenológicos e de produtividade do cupuaçu (Theobroma grandiflorum (Willd. ex Spreng.) Schum.). Acta Amazonica, 13(5/6):725-735.

Fonseca, E.T. 1954. Frutas do Brasil. Instituto Nacional do Livro. Rio de Janeiro. 281 p.

Patiño, V.M. 1963. Plantas cultivadas y animales domésticos em América Equinoccial, Tomo 1: Frutales. Cali, Colombia, Imprenta Departamental. 547 p.

Pennington, T.D. 1997. The genus Inga Botany. London, The Royal Botanic Gardens, Kew. 844 p.
Prance, G.T.; Silva, M.F. 1975. Arvores de Manaus. Manaus, Instituto Nacional de Pesquisas da Amazônia. 312 p.

Ranzani, G. 1980. Identificação e caracterização de alguns solos da Estação Experimental de Silvicultura Tropical do Instituto Nacional de Pesquisa da Amazônia. Acta Amazonica, 10(1):7-4.

Ribeiro, M.N.G. 1976. Aspectos climatológicos de Manaus. Acta Amazonica, 6(2): 229-233

Ribeiro, M.N.G.; Adis, J. 1984. Local rainfall variability - a potential bias for bio-ecological studies in the Central Amazon. Acta Amazonica, 14(1/2):159-174.

Salazar, A.; Szott, L.; Palm, C. 1993. Crop-tree interactions in alley cropping systems on alluvial soils of the Upper Amazon Basin. Agroforestry Systems, 22(1):67-82.

Villachica, H. 1996. Frutales y hortalizas promisorios de la Amazônia. Lima, Perú, Tratado de Cooperação Amazônica. 367 p. 